\title{
Celiac artery compression: Dunbar syndrome
}

\author{
Síndrome da compressão da artéria celíaca (síndrome de Dunbar)
}

Giovanna Mezzalira Santos', Luiz Marcelo Aiello Viarengo', Marcos Danillo Peixoto Oliveira ${ }^{1,2}$ (D)

\begin{abstract}
Celiac artery compression syndrome, also referred to as median arcuate ligament syndrome, celiac axis syndrome or Dunbar syndrome is a rare disorder consequent to extrinsic compression of the celiac trunk by the median arcuate ligament. Doppler ultrasound, multi-slice computed tomography angiography, magnetic resonance angiography, or invasive selective angiography can identify stenosis of the initial segment of the celiac artery and confirm diagnosis. Treatment options include open surgical or videolaparoscopic section of the median arcuate ligament and the fibers of the celiac plexus, or percutaneous transluminal angioplasty via an endovascular approach. We report herein an interesting case of a 38-year-old woman diagnosed with this rare condition and successfully treated with the surgical strategy.
\end{abstract}

Keywords: Dunbar syndrome; celiac artery compression syndrome; median arcuate ligament syndrome.

\begin{abstract}
Resumo
A síndrome da compressão da artéria celíaca, também denominada síndrome do ligamento arqueado mediano, síndrome do eixo celíaco ou síndrome de Dunbar, é uma doença rara causada pela compressão extrínseca do tronco celíaco pelo ligamento arqueado mediano. Ultrassonografia Doppler, angiotomografia computadorizada, angiorressonância magnética ou angiografia seletiva invasiva conseguem identificar a estenose do segmento inicial da artéria celíaca e confirmar o diagnóstico. As opções de tratamento incluem secção videolaparoscópica ou laparotômica (a céu aberto) do ligamento arqueado mediano e das fibras do plexo celíaco, assim como angioplastia transluminal percutânea. Relatamos o interessante caso de uma mulher de 38 anos de idade diagnosticada com essa rara condição e adequadamente tratada pela estratégia cirúrgica.
\end{abstract}

Palavras-chave: síndrome de Dunbar; síndrome da compressão da artéria celíaca; síndrome do ligamento arqueado mediano.

How to cite: Santos GM, Viarengo LMA, Oliveira MDP. Celiac artery compression: Dunbar syndrome. J Vasc Bras. 2019;18:e20180094. https://doi.org/10.1590/1677-5449.009418

\footnotetext{
'Universidade de Taubaté - UNITAU, Faculdade de Medicina, Taubaté, SP, Brasil.

${ }^{2}$ Hospital Regional do Vale do Paraíba, Departamento de Cardiologia Intervencionista, Taubaté, SP, Brasil.

Financial support: None.

Conflicts of interest: No conflicts of interest declared concerning the publication of this article.

Submitted: October 07, 2018. Accepted: December 06, 2018.
}

The study was carried out at Universidade de Taubaté (UNITAU), Taubaté, SP, Brazil. 


\section{INTRODUCTION}

First described by Harjola ${ }^{1}$ in 1963 and Dunbar et al. ${ }^{2}$ in 1965, celiac artery compression syndrome (CACS), also referred to as median arcuate ligament syndrome (MALS), celiac axis syndrome (CAS), and Dunbar syndrome is a rare disorder consequent to extrinsic compression of the celiac trunk by the median arcuate ligament. ${ }^{3}$

CACS is more prevalent in children and adolescents and is associated with specific symptoms, mainly during expiration. Symptoms include the classic triad of mesenteric ischemia: postprandial abdominal pain, nausea, and vomiting and subsequently weight loss. ${ }^{4,5}$ Pain is linked to compression of the celiac trunk (and probably also the celiac plexus) at the level of the diaphragm, due to insertion of the arcuate ligament at a lower level. ${ }^{3}$

Once the syndrome is suspected, Doppler ultrasound (US), multi-slice computed tomography angiography (MSCTA), magnetic resonance angiography, or invasive selective angiography can identify stenosis of the initial segment of the celiac artery and confirm diagnosis. Treatment options include open surgical or videolaparoscopic section of the median arcuate ligament and the fibers of the celiac plexus, or percutaneous transluminal angioplasty via an endovascular approach. ${ }^{4,5}$

We report herein an interesting case of a 38 -yearold woman diagnosed with this rare condition and successfully treated using the surgical strategy.

\section{CASE DESCRIPTION}

An active, Caucasian, otherwise healthy 38-year-oldwoman was found to have a high mesogastric murmur, exacerbated during deep expiration. The remainder of her clinical examination was unremarkable, except for the presence of superficial varicose veins in her legs. Her complaints were post-prandial abdominal pain, dyspepsia, and post-exertional fatigue. Initial Doppler
US (Figure 1) and subsequent MSCTA (Figure 2) suggested and confirmed, respectively, extrinsic celiac artery compression by the median arcuate ligament, compatible with CACS. In view of her symptoms, which were causing significant food intake restrictions and weight loss, surgical (laparotomic) treatment of the condition was proposed to the patient. The procedure was undertaken uneventfully and successfully, with section of the median arcuate ligament and the fibers of the celiac plexus. Three months later, the patient is totally free from any symptoms and a follow-up MSCTA (Figure 3) showed decompression of the celiac trunk.

\section{DISCUSSION}

CACS, MALS, CAS or Dunbar syndrome is a rare vascular compression syndrome, characterized by postprandial intestinal angina caused by impaired blood supply from the celiac artery to the gastrointestinal tract. The median arcuate ligament is located at the T12-L1 level and bridges the crura of the diaphragm, just anterior to the aorta. The celiac plexus is located between the arcuate ligament and the celiac trunk in up to $25 \%$ of normal individuals. Compression of the celiac trunk is, among other causes, secondary to diaphragm descensus after a period of accelerated growth in adolescents. ${ }^{3-5}$

The condition has a 3:1 female to male ratio and the classic patient is a woman aged between 18 and 30 years. ${ }^{3-5}$ Our patient was a 38 year-old woman and abdominal pain was her main symptom.

CACS is a rare entity, which is diagnosed in only 2 of 100,000 patients with ambiguous upper abdominal pain. ${ }^{6}$ The incidence of this disease is not known and typical symptoms are chronic or recurring epigastric pain (especially post-prandial), nausea, vomiting, diarrhea, weight loss, epigastric bloating, and reduced appetite. Since these symptoms may be caused by other diseases, like esophagitis,
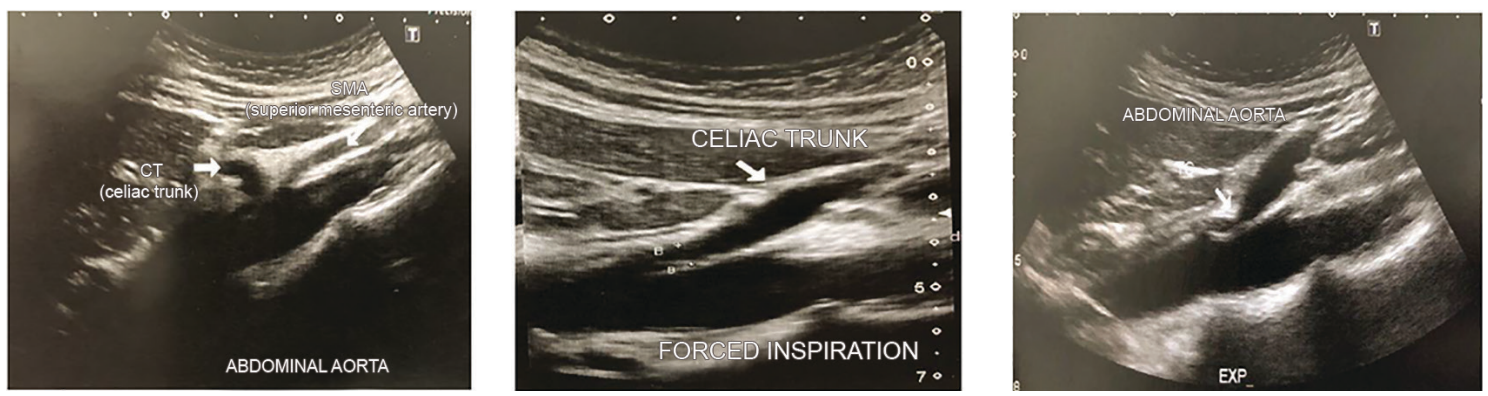

Figure 1. US images showing end-expiratory (right panel) compression of the CT. Left panel, at rest; central panel, with deep inspiration; right panel, with deep expiration. $C T$ = celiac trunk; SMA = superior mesenteric artery; EXP = expiration. 


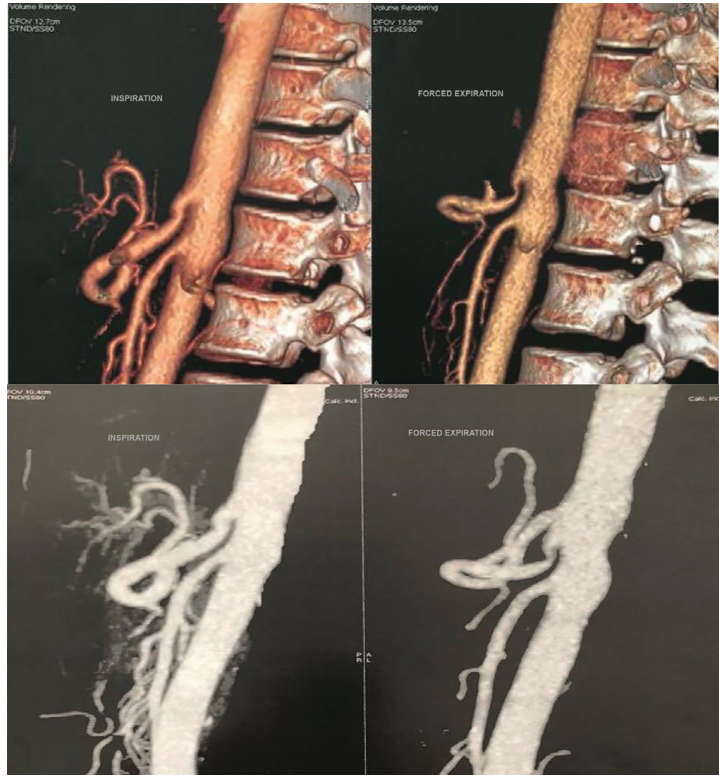

Figure 2. Multi-slice computed angiotomography with respiratory maneuvers - inspiration (left panels) and expiration (right panels). The typical hook-like downward stenosis of the celiac artery is due to the extrinsic compression by the arcuate ligament, especially at deep end expiration (right superior and inferior panels).
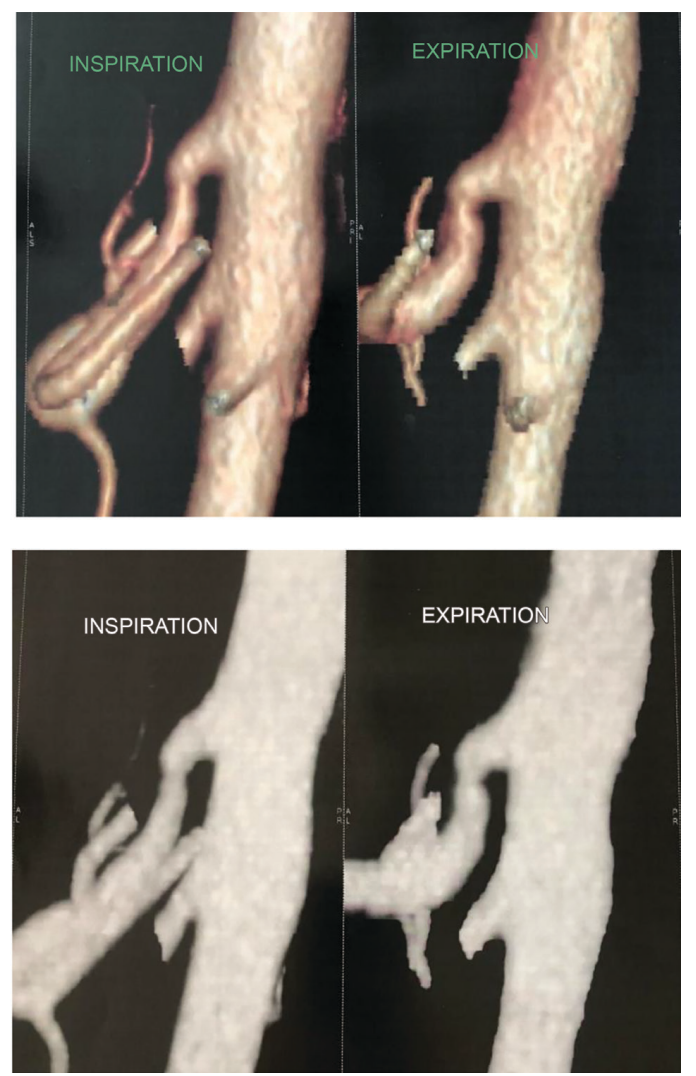

Figure 3. Postoperative multi-slice computed angiotomography with respiratory maneuvers - inspiration (left panels) and expiration (right panels) showing decompression of the celiac trunk. pancreatitis, cholelithiasis, and food intolerance, CACS is a diagnosis of exclusion..$^{3-5}$

The classic manifestation of abdominal angina is seen in about $40 \%$ of patients. Two theories have been suggested to explain symptoms: compression of the mesenteric artery with mesenteric ischemia and splanchnic vasoconstriction due to stimulation of the celiac ganglion and celiac plexus. ${ }^{3-5}$ Pain seems to be related to mechanical irritation of the celiac plexus nerve fibers. As in the present case, an epigastric bruit may be detected on clinical examination.

CACS can be investigated with Doppler US, MSCTA, magnetic resonance angiography, and selective invasive angiography. Doppler US has high sensitivity for diagnosis and has been proposed as the modality of choice, although the gold standard diagnostic method is still selective angiography, which should be performed during both inspiration and expiration. However, the introduction of MSCTA has enabled acquisition of thinner images, providing increased resolution, improved lesion detection, and excellent multiplanar reconstructions. ${ }^{7}$ Since stenosis is respiratory-dependent and becomes more obvious with deep expiration, respiratory maneuvers are needed for diagnosis. The classic hook-like downward displacement followed by a dilatation of the celiac artery is a typical finding. ${ }^{3-7}$ The present case was diagnosed using Doppler US and MSCTA.

Treatment modalities include endovascular (percutaneous transluminal angioplasty with stent implantation) and open (laparotomic) or videolaparoscopic surgical procedures. ${ }^{4,5}$ The first option does not always solve the problem of extrinsic compression and surgical intervention is sometimes needed. ${ }^{3-7}$ Symptomatic patients with confirmed CACS will benefit more from surgical treatments, based on direct visualization and division of the arcuate ligament to achieve decompression of the celiac artery. In some cases, reconstruction of the artery or interposition of a graft is necessary. Decompression by minimally invasive surgery should be the treatment of choice. Laparoscopic techniques and, more recently, robotically-assisted decompression have been reported as safe treatment modalities. ${ }^{3-7}$

In the present case, the choice of technique (open surgery) was based on the surgical team's experience, whose previous cases treated by laparoscopy had not been fully decompressed, especially when there was a strong fibrotic band and the celiac ganglion was involved in the compression, as in this case. In our opinion, laparoscopic surgery is much more time-consuming and generally incomplete, most likely because of fear of accidentally causing an arterial injury. 
In conclusion, CACS is a rare and uncommon cause of postprandial abdominal pain and should be kept in mind after eliminating all other commonly encountered causes. Open surgery is an effective and safe treatment option in selected symptomatic patients, with good long-term results.

\section{REFERENCES}

1. Harjola PT. A rare obstruction of the coeliac artery: report of case. Ann Chir Gynaecol Fenn. 1963;52:547-50. PMid:14083857.

2. Dunbar JD, Molnar W, Beman FF, Marable SA. Compression of celiac trunk and abdominal angina. Am J Roentgenol Radium Ther Nucl Med. 1965;95(3):731-44. http://dx.doi.org/10.2214/ ajr.95.3.731. PMid:5844938.

3. Torres OJ, Gama-Filho OP, Torres CC, Medeiros RM, Oliveira CMB. Laparoscopic treatment of Dunbar syndrome: A case report. Int J Surg Case Rep. 2017;37:230-2. http://dx.doi.org/10.1016/j. ijscr.2017.06.056. PMid:28738298.

4. Gander S, Mulder DJ, Jones S, Ricketts JD, Soboleski DA, Justinich CJ. Recurrent abdominal pain and weight loss in an adolescent: celiac artery compression syndrome. Can J Gastroenterol. 2010;24(2):913. http://dx.doi.org/10.1155/2010/534654. PMid:20151065.

5. Bobadilla JL. Mesenteric ischemia. Surg Clin North Am. 2013;93(4):92540, ix. http://dx.doi.org/10.1016/j.suc.2013.04.002. PMid:23885938.

6. Shetty R, Subramanyam K, Jacob CS. Dunbar syndrome: a rare presentation of abdominal angina treated by revascularization of the celiac artery by endovascular stenting. Int J Res Med Sci. 2018;6(6):2169-71. http://dx.doi.org/10.18203/2320-6012. ijrms20182308.

7. França $\mathrm{LH}$, Mottin C. Surgical treatment of Dunbar syndrome. J Vasc Bras. 2013;12(1):57-61. http://dx.doi.org/10.1590/ S1677-54492013000100012.
Correspondence Marcos Danillo Peixoto Oliveira Universidade de Taubaté - UNITAU, Departamento de Medicina Av. Tiradentes, 500 - Bom Conselho CEP 12030-180 - Taubaté (SP), Brazil Tel.: +55 (12) 3634-2888 E-mail:mdmarcosdanillo@gmail.com

Author information GMS - Medical student, Universidade de Taubaté (UNITAU). LMAV - MD, Pontifícia Universidade Católica de Campinas; Residency in General Surgery and Vascular Surgery, Hospital do Servidor Público Estadual de São Paulo (HSPE-IAMSPE); PhD in

Surgery, Universidade Estadual de Campinas; Vascular surgeon and sonographer; Board-certified, Sociedade Brasileira de Angiologia e Cirurgia Vascular (SBACV) (RQE 14773); Full member, SBACV and Society for Vascular Surgery (SVS); Director, Clínica Viarengo, specialized in Noninvasive Vascular Diagnosis, Angiology, Vascular and Endovascular Surgery.

MDPO - MD, Universidade Federal de Sergipe (UFS); Interventional cardiologist, Hospital das Clínicas, Universidade Federal de Minas Gerais (HC-UFMG); Interventional cardiologist, Hospital Regional do Vale do Paraíba; Preceptor, School of Medicine and Residency Program in Clinical Medicine, Hospital Universitário de Taubaté and Universidade de Taubaté; Critical care physician, UTI-Hospital Pérola Byington; Board-certified in Hemodynamics and Interventional

Cardiology, Sociedade Brasileira de Hemodinâmica e Cardiologia Intervencionista ( $\mathrm{SBHCl}$ ), Sociedade Brasileira de Cardiologia (SBC), and Associação Médica Brasileira (AMB); Medical residency/ board-certified in Hemodynamics and Interventional Cardiology, Instituto do Coração, Hospital das Clínicas, Faculdade de Medicina, Universidade de São Paulo (InCor-HCFMUSP); Board-certified in

Cardiology by SBC and AMB; Medical residency/board-certified in Cardiology, Instituto Dante Pazzanese de Cardiologia; Instructor, Advanced Cardiovascular Life Support (ACLS) course, American Heart Association (AHA); Medical residency/board-certified in Clinical Medicine, Hospital Universitário, Universidade Federal de Sergipe (HU-UFS).

Author contributions Conception and design: GMS, LMAV, MDPO Analysis and interpretation: GMS, MDPO

Data collection: MDPO, GMS Writing the article: MDPO, GMS Critical revision of the article: MDPO Final approval of the article*: GMS, LMAV, MDPO Statistical analysis: N/A.

Overall responsibility: MDPO

*All authors have read and approved of the final version of the article submitted to J Vasc Bras. 